\title{
Pyoderma Gangrenosum with an Underlying Leukocyte Adhesion Deficiency Type 1 (LAD-1) and Pregnancy in the Shade of COVID-19 Epidemic: A Patient and Physician Experience
}

\author{
Aleksandra Opalińska • Adrian Burdacki - Konrad Kwaśniak • \\ Katarzyna Pogoda $\cdot$ Jacek Tabarkiewicz $\cdot$ Adam Reich (D)
}

Received: January 19, 2021 / Published online: March 8, 2021

(c) The Author(s) 2021

\section{ABSTRACT}

In the first part of this article, the anonymous patient diagnosed with leukocyte adhesion deficiency type 1 (LAD-1) and pyoderma gangrenosum (PG) discusses her experience of her medical history and treatment in a foreign country during her pregnancy and the coronavirus disease19 (COVID-19) pandemic. The patient's dermatologists, immunologist, and diagnostician refer to the epidemiology, genetics, diagnosis, morphologic manifestations, including skin lesions, treatment, and prognosis in LAD-1. The patient's diagnostic and therapeutic process was discussed in the last part of this paper.

Supplementary Information The online version contains supplementary material available at https:// doi.org/10.1007/s13555-021-00507-x.

A. Opalińska · A. Reich $(\varangle)$

Department of Dermatology, Institute of Medical Sciences, Medical College of Rzeszow University, Rzeszów, Poland

e-mail: adi_medicalis@go2.pl

\section{A. Burdacki}

Department of Hematology, Institute of Medical Sciences, Medical College of Rzeszow University, Rzeszów, Poland

K. Kwaśniak · K. Pogoda · J. Tabarkiewicz Department of Immunology, Institute of Medical Sciences, Medical College of Rzeszow University, Rzeszow, Poland
Keyword: COVID-19; Cyclosporine; Leukocyte adhesion deficiency type 1 ; Prednisolone; Pregnancy; Pyoderma gangrenosum

\section{Key Summary Points}

Leukocyte adhesion deficiency type 1 (LAD-1) is a rare, life-threatening autosomal recessive primary immunodeficiency syndrome caused by the mutation of integrin $\beta 2$ (CD18) gene.

The most distinctive features of LAD-1 are persistent leukocytosis with neutrophilia and recurrent serious bacterial or fungal infections of the skin and soft tissues.

Patients suffering from severe LAD-1 often die before the age of 2 years as a result of sepsis and require a prompt hematopoetic stem cell transplantation, which is currently the only curative treatment option for any patient diagnosed with LAD-1.

The diagnosis of LAD-1 should be considered in any child and young adult with pyoderma gangrenosum (PG) or PGlike wounds and significant leukocytosis.

Known PG therapies such as steroids and cyclosporine may be effective in treating patients diagnosed with LAD-1 and PG, but it is only a symptomatic, not a curative treatment. 


\section{DIGITAL FEATURES}

This article is published with digital features, including a summary slide, to facilitate understanding of the article. To view digital features for this article go to https://doi.org/10.6084/ m9.figshare.14038979.

\section{PATIENT'S EXPERIENCE}

I was born in a small village in Ukraine and grew up like my peers. I didn't get sick more often and differently than other children, until I was 13. Then, deep wounds on my left lower limb appeared after some minor trauma and they were not healing. I also had sepsis at the time and got a lot of antibiotics in the hospital. This time, the doctors performed some additional tests and diagnosed me with leukocyte adhesion deficiency type 1 (LAD-1). If I remember correctly, we did not receive any special recommendations for the future. When my skin lesions cured leaving scars (Supplementary Fig. 1a, b), I started to continue my normal life as before. Meanwhile, some smaller skin lesions appeared on the skin of my chin, thighs, and hips, which also healed with scarring (Supplementary Fig. 1c). But neither I nor anyone else around me paid much attention to it.

When I was 20, I got married and got pregnant. Two months later, new skin lesion similar to a boil occurred on my left thigh. At first, I treated myself using a home medical kit, as it was not my first such kind of wound, but there was no improvement. The wound did not heal and was getting bigger day by day. I have started to fever to $37.5^{\circ} \mathrm{C}$ within 4 weeks from the first symptoms and I went to the nearest hospital in my area. The treatment there took a week, but to no avail. The wound grew larger (Fig. 1) and my temperature rose to $38.5^{\circ} \mathrm{C}$. I started to walk less because of the terrible pain. Hence, after 7 days of hospitalization, I was referred to another bigger hospital (to the surgery ward) where the wound was mechanically cleaned (Fig. 2). It made my condition even worse. Meantime, I was treated by many antibiotics and had stomachache and diarrhea because of them, luckily, for only a few days.

And the most important thing: I was still worried about what would happen to my unborn child. The doctors in Ukraine strongly suggested to me that my pregnancy will end badly... And my husband was so happy and has been still waiting for his son... Terrible pain that made me stop walking for a month and I could not even straighten my leg anymore. I thought then that, if a little more happened, I would not overcome it. The surgeons had no idea what next to do with me. But I am convinced they did their best. They saved me from sepsis and made excellent photo-documentation, which was very helpful for the next steps.

I and my husband started to think: what can we do? How will I be saved? My husband has been working in Poland for 2 years. Fortunately, he speaks Polish quite well and has some sincere friends there. They helped him to contact Prof. Adam Reich and I was admitted to his Department of Dermatology in Rzeszów. The professor looked at the photos, listened to my story, and agreed to transport me to Poland despite the difficulties related to the coronavirus disease-19 (COVID-19) pandemic. Even the local government was forewarned of my arrival, because the Polish-Ukrainian border was closed for passengers. It was a really, really long way for me, not because of the distance, but because of the procedures we had to follow. I was transported to the border by an ambulance with an Ukrainian doctor, then we were waiting many hours at the border crossing. We followed epidemiological procedures and I was transferred to the ambulance with the Polish medical team. I was very tired and afraid of what would happen next, and the relentless pain was terrible.

In the Department of Dermatology in Rzeszów I got a small hospital room with my husband. We had PCR (polymerase chain reaction) test for COVID-19 three times in Ukraine and the fourth one after my admission... My husband had to be there with me to translate from Polish to Ukrainian as we both do not speak a word of English. Fortunately, he learned Polish quickly, like many of my countrymen working in Poland. As I have never been there before, I did not understand anything in Polish. I must 


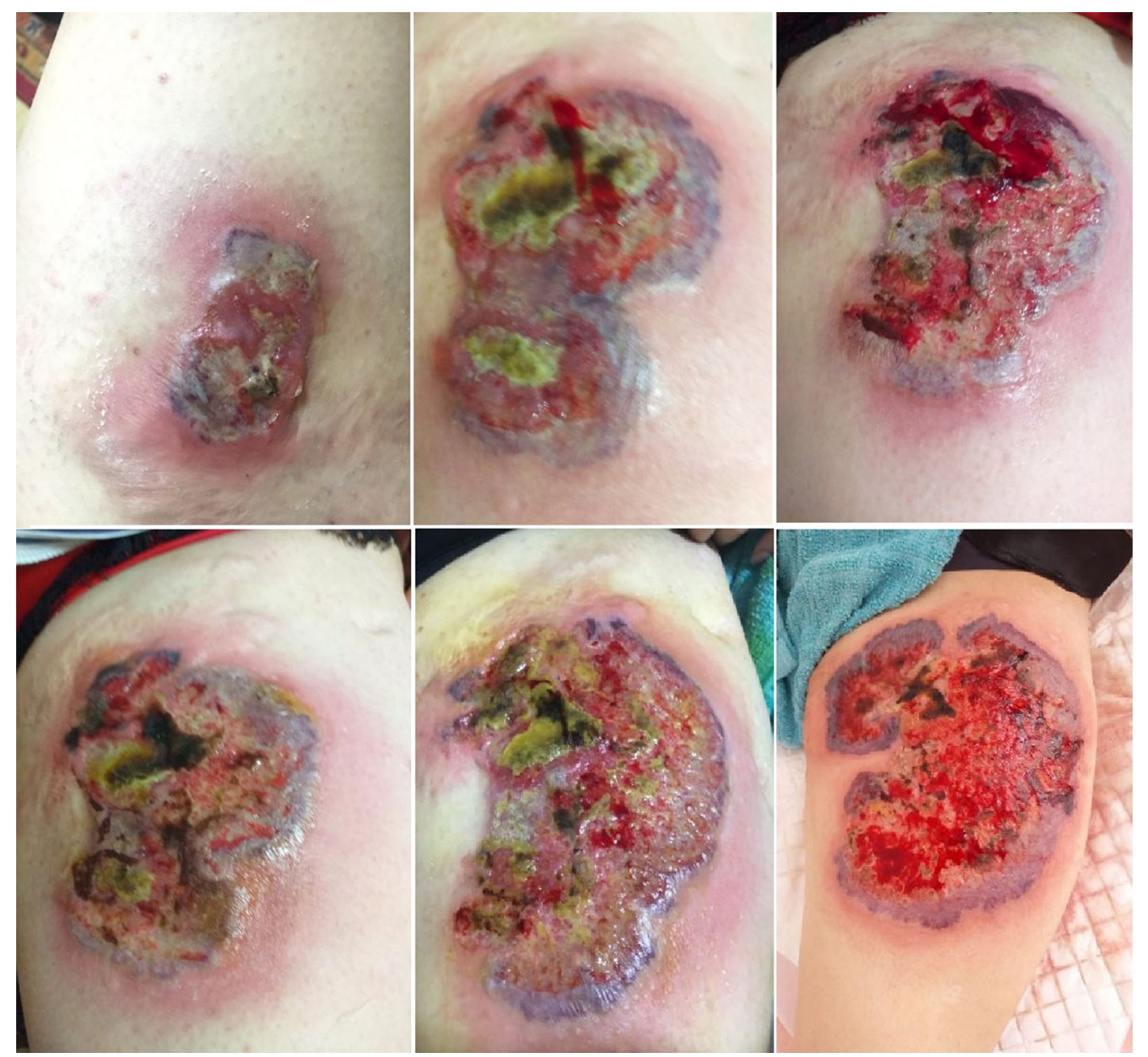

Fig. 1 Evolution of the skin lesions on the left thigh within 2 months before hospitalization in the Department of Dermatology

admit that some words are similar, but not so much that you would communicate easily at once.

The first challenge was to change the dressing that I had had on my wound for 3 days. Pain, shooting pain... I got high doses of paracetamol, but it was still not good. That was why intravenous narcotic drug was added to the therapy. Then I heard quickly that my rehabilitation is necessary and I have to do my best to stand on my own feet as soon as possible. At the same time the laboratory tests and gynecological consultation were performed. We were so lucky to see our baby in the ultrasound pictures! Just amazing! We were also informed, that a serious systemic therapy was necessary and the choice of drugs would take into account my pregnancy. Honestly, I did not think much about that. I knew that I must be treated effectively and needed treatment immediately, because otherwise...

The treatment started and everyday I waited for improvement. I was also impatiently waiting for each narcotic drip during the first days. And the following questions were in my head: Will it ever heal? If yes, then when? Will I survive it? What about my baby? My husband still supported and helped me. He bathed me and even carried me in his arms to the toilet. Meantime, just in a few days, we noticed that my wound started to heal slightly and, most importantly, disease progression had been inhibited. Day 


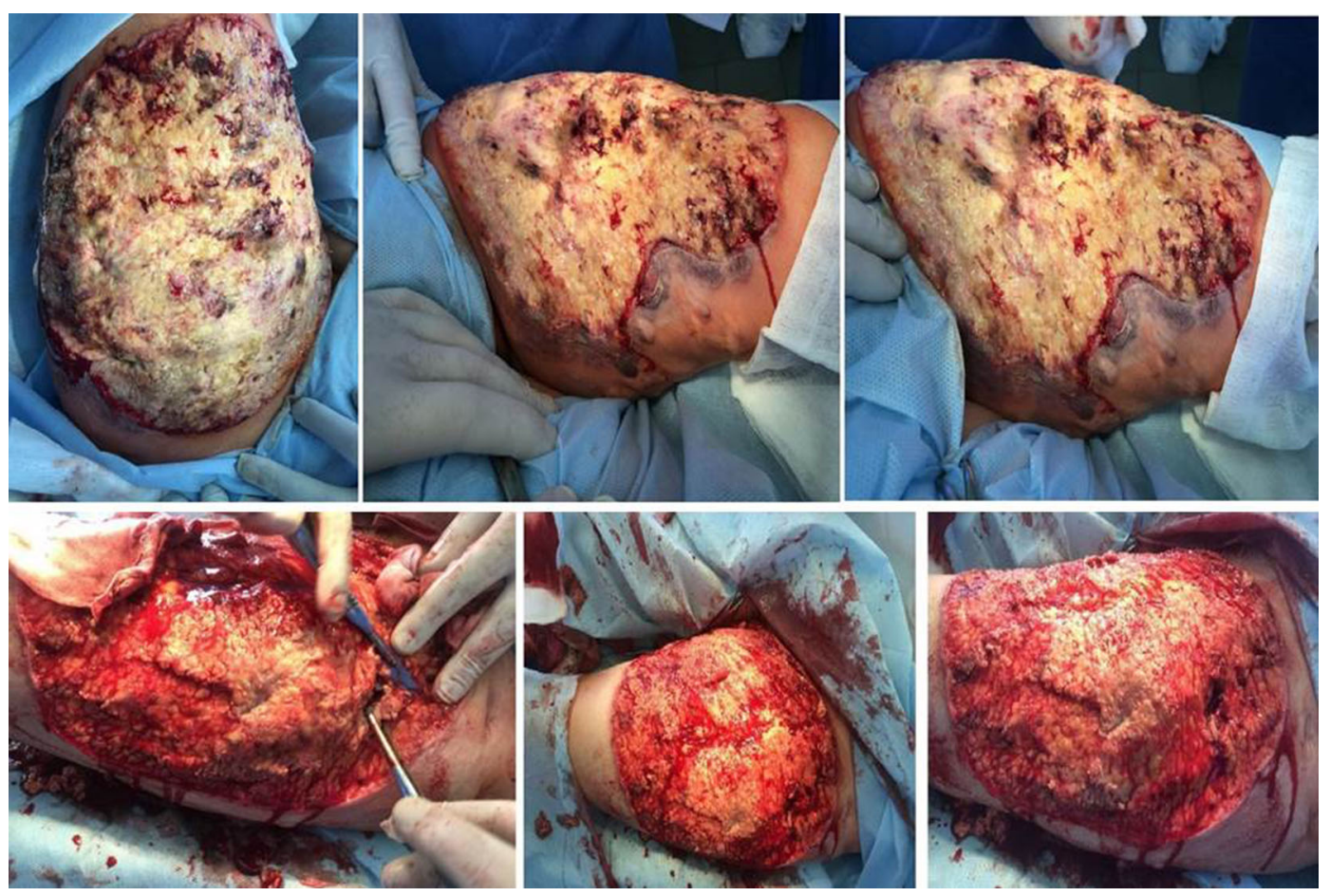

Fig. 2 Ulceration of the left thigh 1 week before hospitalization in the Dermatology Department: shortly before (upper raw) and during (lower raw) surgical debridement in the surgery ward

after day I began to believe that I would succeed. First time I stayed in hospital for 3 weeks. After that hospitalization, I was able to dechallenge all pain drugs. We stayed in Poland, continuing oral and topical treatment. My wound was getting slowly better and smaller.

Then, I was rehospitalized in August, when we heard that everything was proceeding along the right lines at the time. The doctors said that I should continue treatment and follow-up visits in Poland. We knew they wanted the best for us, but we decided to go back to Ukraine. We did not tell them this outright but we knew my doctor, Dr. Aleksandra Opalińska, guessed we would do it. She gave us her email and phone number and we were sure that she would try to help us as much as possible. We contacted each other regularly. I have been continuing treatment in my area and I gave birth to my son a few months later.

I am aware that I received the necessary and professional help. Probably my life and my child's life were saved in this way. For this reason, thank you all for your professionalism, care, and good heart for me-a patient from another country. I am very grateful to my doctors, my husband, and his Polish friends. I know it will not be the end of my story for me. As a result of my illness, I will have to be under constant medical supervision because this kind of skin change can recur in my case at any time. My son will also undergo genetic tests soon.

\section{PHYSICIAN'S PERSPECTIVE}

\section{Epidemiology and Pathogenesis of LAD-1}

LAD-1 is a rare $(1 / 1,000,000$ births) autosomal recessive primary immunodeficiency that was first described and considered as a genetically determined syndrome by Hayward et al. in 1979 $[1,2]$. The root of this disorder is heterogeneous germ-line mutations of the integrin $\beta 2$ gene (ITGB2), located on chromosome 21 (21q22.3). Currently, over 200 mutations in ITGB2 gene have been identified, including deletions, insertions, splice site, nonsense, and missense 
mutations [3-5]. These genetic defects usually lead to absence or reduced expression of the $\beta 2$ (cluster of differentiation, CD18) integrin proteins. Sporadically, normal levels of CD18 are found in LAD-1; however, the CD11/CD18 heterodimers are then functionally compromised $[6,7]$. Thereafter, many leukocyte functions such as chemotaxis, phagocytosis, margination, aggregation, cell-mediated killing, adhesion to the endothelium, and migration through the intravascular space become defective. Consequently, persistent leukocytosis with a high percentage of circulating neutrophils and a low concentration of neutrophils at the site of infection are common in patients with LAD-1. In a normal situation leukocytosis is usually moderate, but in the case of any infection leukocyte counts increase around or above $100,000 / \mathrm{ml}[8,9]$. Additionally, lymphocytic functions are also affected, but not as much as the activity of neutrophils, as these cells also express $\beta 1$ integrin on the surface. Low natural killer (NK) cell and low cytotoxic T lymphocyte activity might be observed as well [8-11].

\section{Classification and Clinical Presentation of LAD-1}

Currently, there is no official and objective classification regarding the severity of LAD-1. Historically, two phenotypes of LAD-1-severe and moderate-have been described, based on the expression level of CD18 on the surface of polymorphonuclear leukocytes. In the literature, different ranges of CD18 level are considered as severe (below $1 \%$ or below $2 \%$ ) or moderate $(2-30 \%)$ [2, 12-15]. There are also known LAD-1 cases in which expression of functionally impaired CD18 on the surface of leukocytes is normal. Moreover, CD18 expression in the same patient may vary significantly depending on the time of testing and other circumstances, such as inflammatory conditions. Thus, in the LAD-1 diagnostic process, expression levels of CD11a-c as well as the clinical picture and search for mutations in the ITGB2 gene should also be considered $[6,16]$.

Clinically, the most distinctive features of LAD-1 are recurrent life-threatening bacterial and sometimes fungal infections of the skin, soft tissues, and mucous membranes with impaired wound healing and inability to form pus. Common presentation includes oral ulcers, perianal and abdominal wall abscesses, fasciitis, dactylitis, and cellulitis. Delayed umbilical cord separation and/or omphalitis during the perinatal period may occur as the first representative symptoms, usually in the more severe forms of the disease. Sepsis and bacteremia are also frequent and often lead to death despite antibiotherapy, both in severe and in mild LAD1 variants. Typically, other infections are also presented, such as otitis media, gingivitis, periodontitis, premature loss of temporary or permanent teeth, enteritis, osteomyelitis, pneumonia, and upper respiratory tract and urinary tract infections [17-19].

\section{Pyoderma Gangrenosum as a Comorbidity of LAD-1}

Patients with LAD-1 are also prone to develop autoimmune disorders, such as Crohn-like colitis, juvenile idiopathic arthritis, pyoderma gangrenosum (PG) or PG-like lesions, that are clinically analogous to PG, but no dermal neutrophilia is found [16, 20-25]. PG itself is an uncommon, serious, ulcerating skin disease with not fully understood etiology. However, it appears to be a disorder of the innate immune system. It is a noninfectious, progressive necrosis of the skin, presented by painful ulcers with undermined violaceous or bluish borders. Currently, there are no standardized treatment guidelines for PG. As the disease is rare, the existing therapeutic recommendations are based mostly on case reports and a few small controlled trials on PG management. The treatment usually combines local wound care and systemic immunosuppression as the mainstay therapy. Among immunosuppressive agents, corticosteroids and cyclosporine are most commonly used. Sometimes, other immunosuppressants, cytostatics, or immune modulators (such as azathioprine, mycophenolate mofetil, methotrexate, thalidomide, interferon alpha (IFN $\alpha)$ intravenous immunoglobulins (IVIg), or biologics, 
predominantly anti-tumor necrosis factor (TNF) inhibitors) are prescribed. The treatment usually depends on personal experience, availability of therapy, and presenting comorbidities [26-29].

\section{Prognosis and Treatment of LAD-1 and Pyoderma Gangrenosum}

LAD-1 and associated disorders, such as infections and autoimmune conditions, are unquestionably life-threatening and require intensive treatment. Regarding severe LAD-1, many patients die before the age of 2 years and most of them before their 5th birthday. In the moderate LAD-1, it is possible to reach adulthood, but serious chronic or acute infections are becoming more and more critical to patients' survival, especially between the 2 nd and 4 th decades of their lives $[9,30]$. Currently, the only potential definite treatment option recommended in LAD-1 is allogeneic hematopoietic stem cell transplantation (HSCT) or umbilical cord blood transplantation (UCBT). The alternative therapeutic options include antibiotic prophylaxis, granulocyte transfusions, and prophylactic IVIg therapy [30-33]. There are also single case reports of the efficacy of infliximab treatment in colitis and arthritis related to LAD-1 [20], and ustekinumab treatment in a patient with sacral ulcer and severe periodontitis [34]. Moreover, many different methods of therapy have been used in the treatment of patients with LAD-1 presenting with PG or PGlike lesions, with varying efficacy, such as systemic glucocorticoids, cyclosporine, infliximab, and other anti-TNF inhibitors, IVIg, HSCT, antibiotics, dapsone, colchicine, anakinra, mycophenolate mofetil, and others [22, 24, 25]. Further research and observations are necessary, but it is very difficult because of the small number of cases of LAD-1 coexisting with this type of skin lesion.

\section{MY PATIENT}

Initially, I heard about my next patient a few days before her admission to our department. In view of the restrictions related to the COVID-19 pandemic, permission for her arrival from
Ukraine to Poland was obtained from the local government. I was looking at the clinical pictures with my department head and I understood immediately that it would be a difficult and challenging case. The first day we met, I saw a 20-year-old pregnant woman, with a large dressing on her left thigh. She suffered so much from the pain that she was unable to walk, sit, or even straighten her left lower limb. She did not speak a word of English and she did not understand Polish. On the other hand, I and the rest of our team do not know Ukrainian. Therefore, I was very content that her husband could be an interpreter; in fact, there was no other option. Besides, his presence cheered her up and reduced the stress she had in this pregnancy anyway. I tried to give her at least my smile, even though we were all wearing masks.

During the anamnesis, I found out that she was at the 16th week of pregnancy and she was currently taking folic acid, dydrogesterone, and iron supplementation because of significant anemia. She has had a progressive ulceration of the left thigh for 2 months (Fig. 1) and she was treated with many antibiotics, such as imipenem/cilastatin, linezolid, levofloxacin, and ornidazole and fluconazole. Finally, the surgical debridement of the wound was performed, which triggered a clinical deterioration (Fig. 2). Furthermore, she suffered from osteomyelitis and sepsis at the age of 13 and she was diagnosed with LAD-1. On the other hand, she had no history of serious recurrent infections or delayed detachment of the umbilical cord. As the tests confirming this diagnosis could not be found in her medical documentation, I knew that I would conduct a thorough diagnosis of this problem.

My first therapeutic challenge was effective and safe analgesia, as it was obvious that paracetamol would not be sufficient. Nalbuphine was added intravenously to the therapy after consultation with a gynecologist and anesthesiologist. Regardless, we removed the first dressing from the wound over $3 \mathrm{~h}$. Then, I saw a huge ulcer on the front, medial, and lateral surfaces of the left thigh, with a purple and undermined edge, covered with necrotic tissues and fibrin, measuring $32 \times 28 \mathrm{~cm}$. The related pain was so strong that I managed to take the 


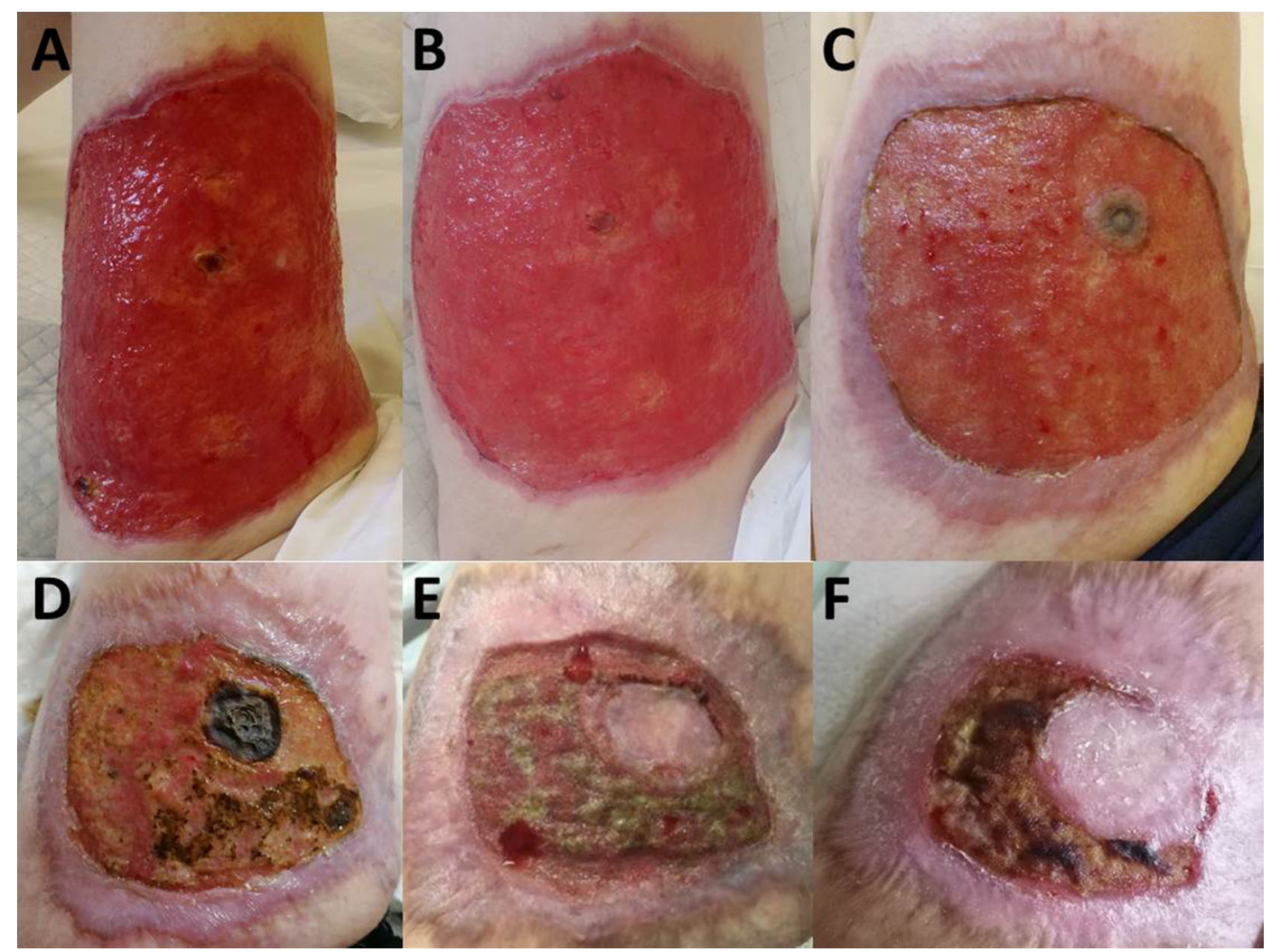

Fig. 3 a, b Ulceration of the left thigh 3 days after beginning of the therapy with cyclosporine and prednisolone. Skin lesion after 1 month (c), 2 months (d), 4 months (e), and 5 months (f) of systemic therapy with cyclosporine and prednisolone

photo only a few days later, when the ulcer was already cleaned by hydrofiber dressings (Fig. 3a, b). At that time, we had no clinical doubts (considering the anamnesis, the presence of pathergy, the current clinical picture, and previous photo documentation) that it was PG. Skin biopsy was not performed because of the patient's lack of consent for this procedure. She suffered a lot from pain and was afraid that it could exacerbate her disease.

Laboratory results revealed high leukocytosis $\left(55,940 / \mathrm{mm}^{3}\right.$; normal values $4000-10,000 /$ $\mathrm{mm}^{3}$ ) with $89.1 \%$ neutrophils and $7.8 \%$ lymphocytes, a normocytic anemia (hemoglobin $7.0 \mathrm{~g} / \mathrm{dl}$; normal values $12.0-16.0 \mathrm{~g} / \mathrm{dl})$, and elevated erythrocyte sedimentation rate $(63 \mathrm{~mm} / \mathrm{h})$. C-reactive protein was slightly elevated $(4.8 \mathrm{mg} / \mathrm{dl}$; normal $<0.5 \mathrm{mg} / \mathrm{dl})$. Procalcitonin, serum immunoglobulin levels, and the rest of laboratory evaluations, including autoantibodies, were normal. The gynecological examination did not reveal any deviations regarding gestation. In addition, flow cytometry revealed markedly decreased expression of CD11b-c and CD18 antigens on granulocyte and monocyte surfaces (Fig. 4, Supplementary Table 1, Supplementary Methods). The in vitro tests also showed the lack of ability of neutrophils isolated from the patient's blood to migrate towards chemoattractant, but their oxidative burst activity measured by flow cytometry remained unaltered, findings typical for LAD-1 syndrome (Fig. 5, Supplementary Methods).

The therapy was initially started with prednisolone $0.6 \mathrm{mg} / \mathrm{kg}$ daily and cyclosporine $4.6 \mathrm{mg} / \mathrm{kg}$ daily. During the first 3 weeks, the prednisolone dose was tapered to $0.15 \mathrm{mg} / \mathrm{kg}$ daily and cyclosporine dose was increased to $5.4 \mathrm{mg} / \mathrm{kg}$ daily, because of the low concentration of its serum level. The wound was dressed with an antimicrobial hydrofiber dressing 

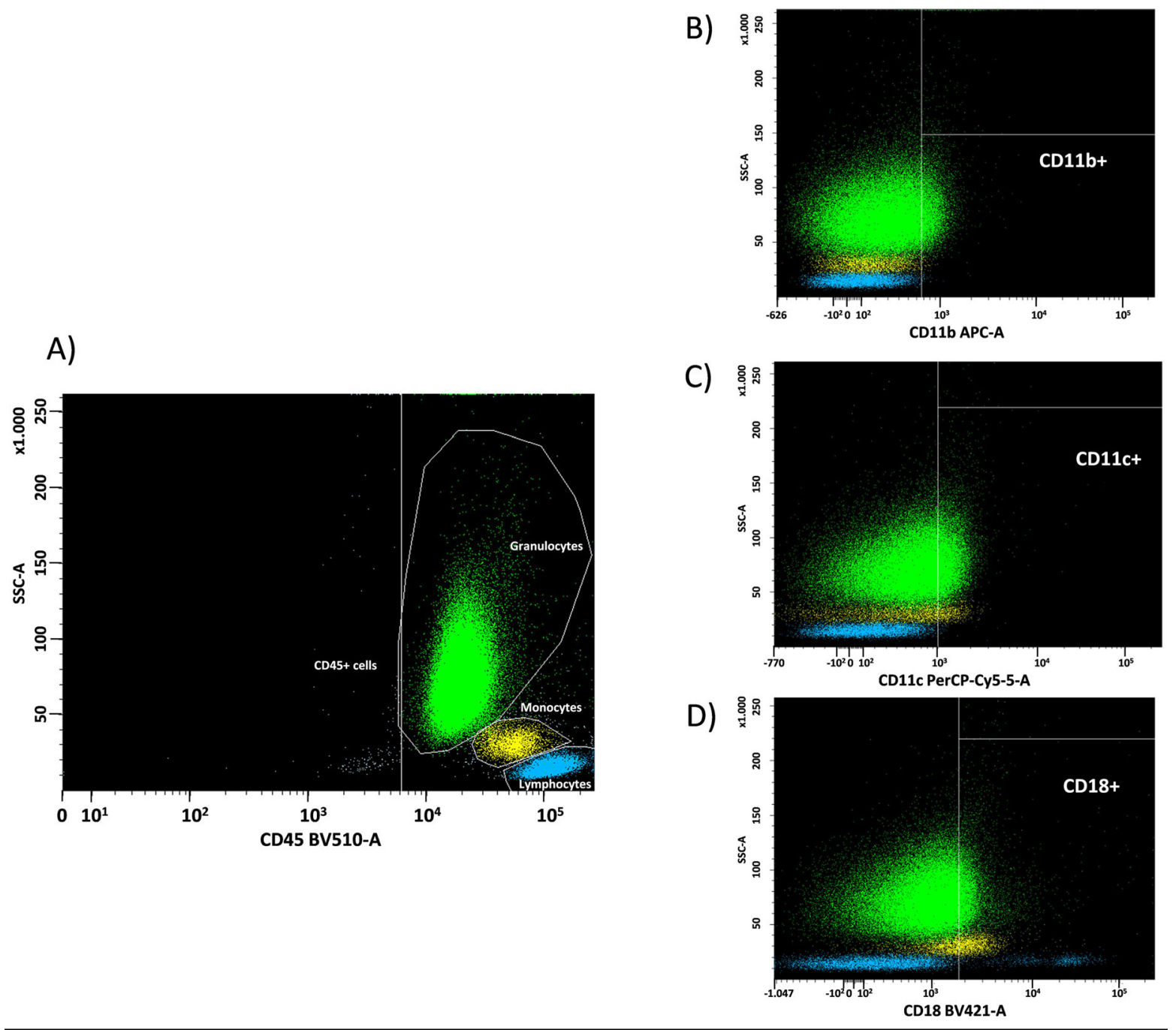

Fig. 4 Monocyte population* (yellow), lymphocyte populations (blue), granulocyte population* (green). Flow cytometry analysis revealed markedly decreased expression of CD11b/CD11c/CD18 antigens in the leukocyte subsets ( ${ }^{*}$ full immunophenotypic profile of monocyte

changed once a day because of the large amount of effusion and necrotic tissue. The additional therapy included physiotherapy, erythrocyte concentrate transfusion, and supplementation of albumin, vitamins, and minerals. The ulcer stabilization and pain reduction was achieved within the first few days of treatment. Thereafter, slight epithelialization appeared at all edges and the wound began to decrease and shrink to $24 \times 27 \mathrm{~cm}$ in 3 weeks. During the follow-up visit at the 7 th week of treatment, a population: $\mathrm{CD} 45^{+} / \mathrm{CD} 16^{-} / \mathrm{CD} 66^{+} \mathrm{dim} / \mathrm{CD} 64^{+}$high/ $\mathrm{CD} 11 \mathrm{~b}^{-} / \mathrm{CD} 11 \mathrm{c}^{-} / \mathrm{CD} 18^{+/-} \mathrm{dim}$; granulocyte population: $\quad \mathrm{CD} 45^{+} \mathrm{dim} / \mathrm{CD} 16^{+}$strong/CD $66^{+}$strong/

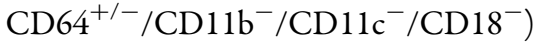

further clinical improvement was observed with a reduction of the ulcer size to $15 \times 21 \mathrm{~cm}$ and white blood cell count to $20,800 / \mathrm{mm}^{3}$. Cyclosporine and prednisolone dosing was further reduced to $3.8 \mathrm{mg} / \mathrm{kg}$ daily and $0.1 \mathrm{mg} / \mathrm{kg}$ daily, respectively.

I strongly urged the patient to stay in Poland and come for follow-up visits to our department. However, I guessed that she and her husband had already made the decision to return to their home. We stay in touch by 


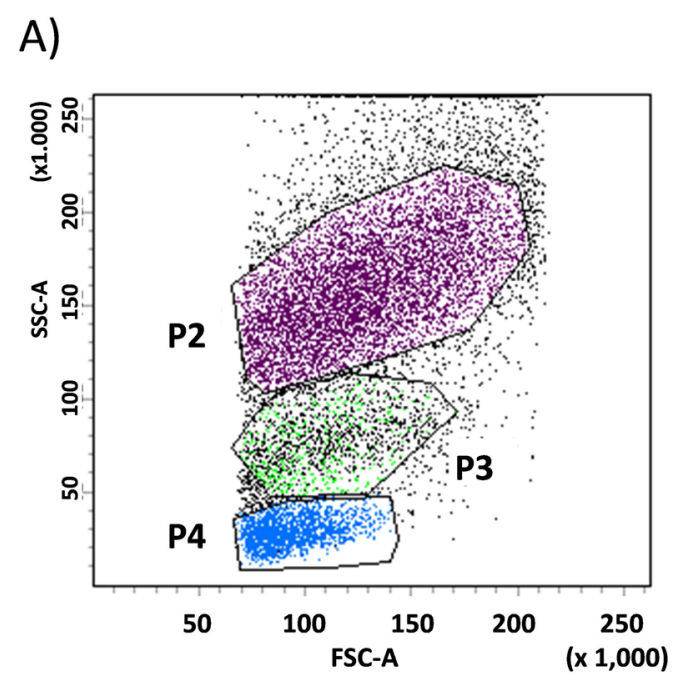

Fig. 5 Results of phagoburst assay: a Granulocytes were gated on FSC/SSC (forward scatter/side scatter) dot plot. b Rhodamine 123 fluorescence intensity in the granulocytes population was detected in the FITC (fluorescein isothiocyanate) channel and the threshold for rhodamine 123 was determined in accordance with the negative

phone and e-mail. Treatment is continued in the patient's area and ulcer healing is progressing successfully. Cyclosporine dose has been systematically tapered and prednisolone was discontinued after 4 months of therapy. During the perinatal period and in the postpartum period ( 5 months from the beginning of the treatment), cyclosporine was maintained at a dose of $100 \mathrm{mg}$ daily $(1.7 \mathrm{mg} / \mathrm{kg})$. During this time, the size of the ulcer decreased to $5 \times 8 \mathrm{~cm}$. The patient's child did not present any disorders a fter delivery. The baby will be
B)

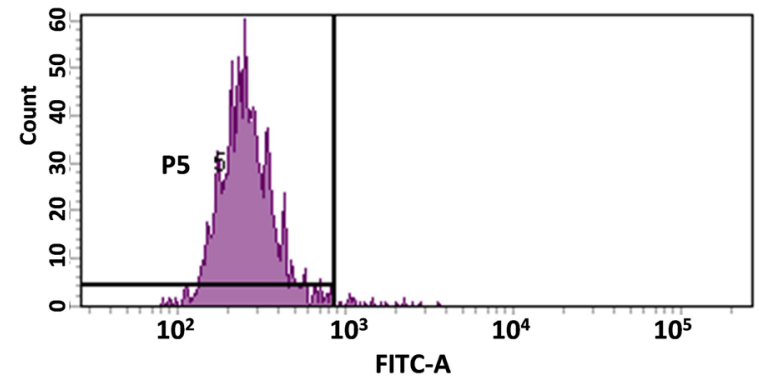

C)

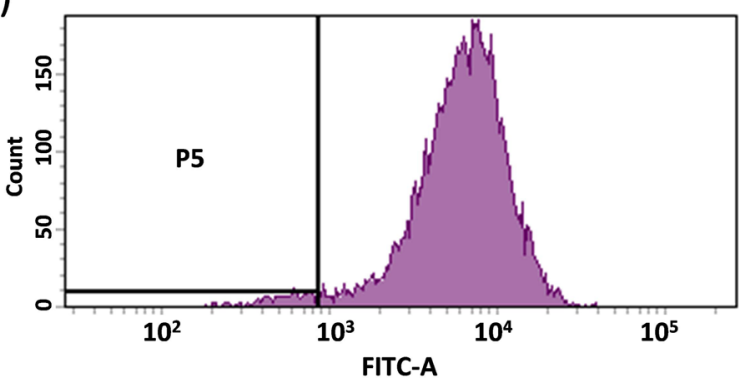

D)

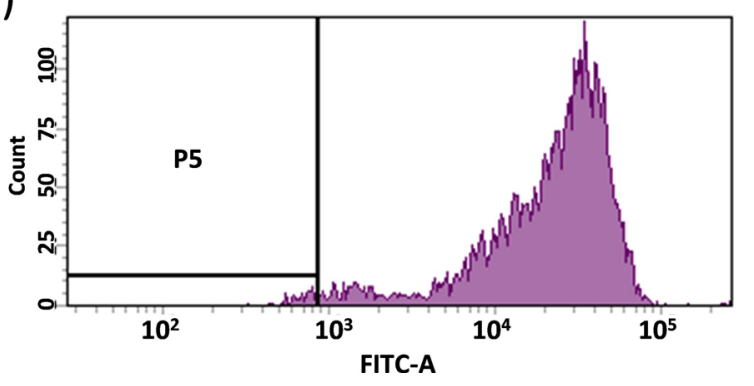

control sample. c Analysis of rhodamine 123 fluorescence in sample stimulated with PMA (phorbol 12-myristate 13-acetate). d Analysis of rhodamine 123 fluorescence in sample stimulated with E. coli confirming normal phagocyte function

under systematic pediatric control and will undergo genetic testing soon. The patient was advised to follow continuous immunological control and to consider HSCT.

\section{ACKNOWLEDGEMENTS}

Funding. No funding or sponsorship was received for this study or publication of this article. 
Authorship. All named authors meet the International Committee of Medical Journal Editors (ICMJE) criteria for authorship for this article, take responsibility for the integrity of the work as a whole, and have given their approval for this version to be published.

Disclosures. Aleksandra Opalińska, Adrian Burdacki, Konrad Kwaśniak, Katarzyna Pogoda, Jacek Tabarkiewicz, and the anonymous patient have nothing to disclose. Adam Reich is a member of the journal's Editorial Baord.

Compliance with Ethics Guidelines. Informed consent for publication of the images within the article was obtained from the patient.

Peer Review. Please note, contrary to the journal's standard single-blind peer review process, as a commentary this article underwent review by a member of the journal's Editorial Board.

Open Access. This article is licensed under a Creative Commons Attribution-NonCommercial 4.0 International License, which permits any non-commercial use, sharing, adaptation, distribution and reproduction in any medium or format, as long as you give appropriate credit to the original author(s) and the source, provide a link to the Creative Commons licence, and indicate if changes were made. The images or other third party material in this article are included in the article's Creative Commons licence, unless indicated otherwise in a credit line to the material. If material is not included in the article's Creative Commons licence and your intended use is not permitted by statutory regulation or exceeds the permitted use, you will need to obtain permission directly from the copyright holder. To view a copy of this licence, visit http://creativecommons.org/licenses/by$\mathrm{nc} / 4.0 /$.

\section{REFERENCES}

1. Hayward AR, Harvey BA, Leonard J, Greenwood MC, Wood CB, Soothill JF. Delayed separation of the umbilical cord, widespread infections, and defective neutrophil mobility. Lancet. 1979;8126: 1099-101.

2. Harris ES, Weyrich AS, Zimmerman GA. Lessons from rare maladies: leukocyte adhesion deficiency syndromes. Curr Opin Hematol. 2013;20:16-25.

3. Hibbs ML, Wardlaw AJ, Stacker SA, et al. Transfection of cells from patients with leukocyte adhesion deficiency with an integrin beta subunit (CD18) restores lymphocyte function-associated antigen-1 expression and function. J Clin Invest. 1990;85: 674-81.

4. van de Vijver E, Maddalena A, Sanal Ö, et al. Hematologically important mutations: leukocyte adhesion deficiency (first update). Blood Cells Mol Dis. 2012;48:53-61.

5. Fagerholm SC, Guenther C, Llort Asens M, Savinko $\mathrm{T}$, Uotila LM. Beta2-integrins and interacting proteins in leukocyte trafficking, immune suppression, and immunodeficiency disease. Front Immunol. 2019;10:254.

6. Levy-Mendelovich S, Rechavi E, Abuzaitoun O, et al. Highlighting the problematic reliance on CD18 for diagnosing leukocyte adhesion deficiency type 1. Immunol Res. 2016;64:476-82.

7. Kuijpers TW, Van Lier RA, Hamann D, et al. Leukocyte adhesion deficiency type 1 (LAD1)/variant. A novel immunodeficiency syndrome characterized by dysfunctional beta2 integrins. J Clin Invest. 1997;100:1725-33.

8. Kohl S, Springer TA, Schmalstieg FC, Loo LS, Anderson DC. Defective natural killer cytotoxicity and polymorphonuclear leukocyte antibody-dependent cellular cytotoxicity in patients with LFA1/OKM-1 deficiency. J Immunol. 1984;133:2972-8.

9. Bednarczyk M, Stege H, Grabbe S, Bros M. $\beta 2$ Integrins-multi-functional leukocyte receptors in health and disease. Int J Mol Sci. 2020;21:1402.

10. Anderson DC, Schmalsteig FC, Finegold MJ, et al. The severe and moderate phenotypes of heritable Mac-1, LFA-1 deficiency: their quantitative definition and relation to leukocyte dysfunction and clinical features. J Infect Dis. 1985;152:668-89.

11. Springer TA. Traffic signals for lymphocyte recirculation and leukocyte emigration: the multistep paradigm. Cell. 1994;76:301-14.

12. Etzioni A. Genetic etiologies of leukocyte adhesion defects. Curr Opin Immunol. 2009;21:481-6.

13. Tone Y, Wada T, Shibata F, et al. Somatic revertant mosaicism in a patient with leukocyte adhesion deficiency type 1. Blood. 2007;109:1182-4. 
14. El-Sayed ZA, El-Ghoneimy DH, Abd-Allah H, Afifi HM. A rare association between leukocyte adhesion deficiency type I and psoriasis in humans. Allergy Asthma Immunol Res. 2011;3:138-40.

15. Vasconcelos Dde M, Beitler B, Martinez GA, et al. CD18 deficiency evolving to megakaryocytic (M7) acute myeloid leukemia: case report. Blood Cells Mol Dis. 2014;53:180-4.

16. De Rose DU, Giliani S, Notarangelo LD, et al. Long term outcome of eight patients with type 1 leukocyte adhesion deficiency (LAD-1): not only infections, but high risk of autoimmune complications. Clin Immunol. 2018;191:75-80.

17. Moutsopoulos NM, Konkel J, Sarmadi M, et al. Defective neutrophil recruitment in leukocyte adhesion deficiency type I disease causes local IL17-driven inflammatory bone loss. Sci Transl Med. 2014;6:229ra40.

18. van de Vijver E, van den Berg TK, Kuijpers TW. Leukocyte adhesion deficiencies. Hematol Oncol Clin North Am. 2013;27:101-16.

19. Movahedi M, Entezari N, Pourpak Z, et al. Clinical and laboratory findings in Iranian patients with leukocyte adhesion deficiency (study of 15 cases). J Clin Immunol. 2007;27:302-7.

20. Marsili M, Lougaris V, Lucantoni M, et al. Successful anti-TNF- $\alpha$ treatment in a girl with LAD-1 disease and autoimmune manifestations. J Clin Immunol. 2014;34:788-91.

21. Uzel G, Kleiner DE, Kuhns DB, Holland SM. Dysfunctional LAD-1 neutrophils and colitis. Gastroenterology. 2001;121:958-64.

22. Simpson AM, Chen $\mathrm{K}$, Bohnsack JF, Lamont MN, Siddiqi FA, Gociman B. Pyoderma gangrenosumlike wounds in leukocyte adhesion deficiency: case report and review of literature. Plast Reconstr Surg Glob Open. 2018;6:e1886.

23. Madkaikar M, Italia K, Gupta M, et al. Leukocyte adhesion deficiency-I with a novel intronic mutation presenting with pyoderma gangrenosum-like lesions. J Clin Immunol. 2015;35:431-4.
24. Cantisani C, Naqeshbandi AF, Goldust M, Lampitelli S, Cantoresi F, Alsorori E. Type I leucocyte adhesion deficiency in Yemenian family managed with appropriate treatment: a case series. Dermatol Ther. 2019;32:e12864.

25. Thakur N, Sodani R, Chandra J, Singh V. Leukocyte adhesion defect type 1 presenting with recurrent pyoderma gangrenosum. Indian $\mathrm{J}$ Dermatol. 2013;58:158.

26. Maverakis E, Marzano AV, Le ST, et al. Pyoderma gangrenosum. Nat Rev Dis Primers. 2020;6:81.

27. Braswell SF, Kostopoulos TC, Ortega-Loayza AG. Pathophysiology of pyoderma gangrenosum (PG): an updated review. J Am Acad Dermatol. 2015;73: 691-8.

28. DeFilippis EM, Feldman SR, Huang WW. The genetics of pyoderma gangrenosum and implications for treatment: a systematic review. Br J Dermatol. 2015;172:1487-97.

29. Goldust M, Hagstrom EL, Rathod D, Ortega-Loayza AG. Diagnosis and novel clinical treatment strategies for pyoderma gangrenosum. Expert Rev Clin Pharmacol. 2020;13:157-61.

30. Almarza Novoa E, Kasbekar S, Thrasher AJ, et al. Leukocyte adhesion deficiency-I: a comprehensive review of all published cases. J Allergy Clin Immunol Pract. 2018;6(1418-20):e10.

31. Chakraborty S, Gupta D, Thakral D, et al. Successful reconstitution of leukocyte adhesion defect after umbilical cord blood stem cell transplant. Cent Eur J Immunol. 2020;45:117-21.

32. Qian X, Wang P, Wang H, et al. Successful umbilical cord blood transplantation in children with leukocyte adhesion deficiency type I. Transl Pediatr. 2020;9:34-42.

33. Wolach B, Gavrieli R, Wolach O, et al. Leucocyte adhesion deficiency-a multicentre national experience. Eur J Clin Invest. 2019;49:e13047.

34. Moutsopoulos NM, Zerbe CS, Wild T, et al. Interleukin-12 and interleukin-23 blockade in leukocyte adhesion deficiency type 1. N Engl J Med. 2017;376: 1141-6. 